A reaction always occurs when there is pathological evidence of tuberculosis, though there may be an absence of clinical evidence. The ophthalmo-reaction should never be employed if any affection of the eye is present. Even apart from these cases it is undoubtedly attended with some risk. This test is more in harmony with clinical experience than von Pirquet's.

My opinion is that neither of these tests is nearly of such diagnostic value as the subcutaneous tests.

\section{THE INFLUENCE OF STRONG, PREVALENT, RAIN-BEARING WINDS ON THE COURSE OF PHTHISIS.}

By WILLIAM GORDON, M.D.CAMB., F.R.C.P.LoNd., PHYSICIAN TO THE ROYAL DEVON AND EXETER HOSPITAL.

I HAve repeatedly-and, I venture to believe, conclusively -shown that strong, prevalent, rain-bearing winds exercise a powerful influence over the prevalence of phthisis. I now propose to show that probably they also exert an influence on the course of the disease.

There are several lines of inquiry which may be followed in order to ascertain whether these winds do exert an influence on the course of phthisis or not. We may (1) make continuous clinical observations on phthisis cases in some single locality under varying conditions of wind and rain; or (2) we may clinically observe and compare the effects on a series of phthisis patients of residence in sheltered and exposed situations; or (3) we may compare the collective results obtained by similar methods at differently located sanatoriums-some in shelter, some exposed; or (4), lastly, we may compare the average durations of fatal cases whose course has been run in places which present a süitable contrast of shelter and exposure.

It is to this last line of inquiry that I would now especially invite attention. I shall only refer to the three others in order to make clear that they all, so far as I have been able to follow them, seem to lead to the same conclusion.

\section{Observation of Patients in a Single Locality Under} Varying Conditions of Wind and Rain.

This is a line of inquiry which lies peculiarly within the province of sanatorium physicians, and to them one must ultimately look for the width of experience requisite to enable us to form a judgement. My own opportunities have been necessarily very limited. But when, some years ago, the "open-air" treatment began to be introduced into this country and when we were treating a number of cases in connexion with the Royal Devon and Exeter Hospital, it seemed to me that windy and rainy weather unfavour. ably affected them. About the same time a friend of mine, who had medical charge of a "home for consumptives" at the top of a hill open to all winds, told me that his patients seemed to get on very well except when westerly winds were blowing. In 1904, Dr. A. A Rodriguez, of Campo in the Azores, was so good as to make inquiries for me amongst the medical men practising in those islands, and told me that, whilst some had noticed no injurious effect from any wind, others had found their phthisical patients were worse when the warm and damp south winds were blowing, and others considered that these south winds did harm and that the north winds, which are dry, did gool. A recent statement by Dr. H. Hyslop Thomson i that :the sanatorium physician knows well that such winds (strong, prevalent, and rain-bearing) are responsible for elevation of temperature and increased cough and expectoration amongst certain of his patients" is of special importance as embodying just the sort of experience which is necessary for the satisfactory following out of this method. Thus such evidence as I am avare of points in the direction of these winds affecting unfavourably the course of phthisis.

\section{Comparison of the Effects on Plithisis Paticnts of} Residence in Sheltered and Exposed Situations.

Here my opportunities have been more extensive, though my observations have been far too limited to be more than suggestive. It is obvious that the personal opportunities of any single observer, not specially devoting himself to the treatment of phthisis, can scarcely, in a dozen years, furnish conclusive evidence by this method. A few ex. amples will suffice to indicate my general experience.

A young lady, after a smart haemoptysis, had been seen by me doing remarkably well in a winḑ-sheltered situation. Bứ, being better, she took it into her head to go for a "bracing change" to one of our most westerly exposed hillsides. A been a success, and she had had another considerable attack of haemorrhage.

A gipsy woman, camping in the open air on the summit of $a$ A gipsy woman, camping in the open air on the summit of $x$ I got her to shift her camp to the leeside of the hill, and imme. I got her to shift her camp to

A man, who had been nursing his son who died of phthisis, dereloped an empyema. After this had been opened, he went to a very sheltered valley in South Devon, where he did ex: ceedingly well. His second son came to me some time afterwards with early phthisis, and, at his father's request, I sent him to the same place. I have rarely seen so rapid and complete a recovery as the boy made.

A lady with very slight disease of one apex, which had steadily refused to clear ul, spent the winter at Chagford, and whei I saw her next spring the physical signs had practically dis. appeared. She went to an exposed health resort in another county, and tre:e the disease broke out afresh.

This north-east slope of Dartmoor, to which I drev attention in 1900 for its comparative shelter from westerly winds and coincidentally low phthisis mortality, has since then veen utilized for sanatoriums, which have given very satisfactory results, as I cain testify from the cases which I have sent to them:

On the other hand, I have seen cases at various points along our southern sea-board, who had been sent from a distance to live on the actual sea-front, and had been promptly seized with acute chest complications or with haemoptysis. Yet cases suitably located, in sheltered spots at these very health resorts, do exceedingly well. In one of them several excellent medical observers have noticed that cases of. haemoptysis which have proved in. tractable on the actual sea-front, lose their haemorrhages when removed about a quarter of a mile inland, under the shelter of a considerable hill.

Long ago Dr. Thomas Shapter pointed out how un. desirable it is to place a consumptive on an exposed sea. shore, and Dr. Ransome has more recently emphasized the seriousness of the consequences of locating such patients on an exposed sea-front. ${ }^{2}$ It seems to me, however, that simple aspect has a good deal to do with the effect. 'Thus, I remember a patient who had greatly improved in hospital, insisting on returning home to live in the open air at a seaside place which faces almost due east with considerable western slielter. She continued to do very well so long as I had news of her. . Also it is not entirely a matter of distance from the sea, for a case which did badly with repeated haemoptysis, lived on a high hill facing west just above a sheltered seaside town, in which, not far from the beach, several cases I know have done satisfactorily.

An interesting observation comes from the Sandwich Islands. This group is said by $\mathrm{Hann}^{3}$ to present "the finest example of the contrast" between a wet and windy side and a dry. and sheltered side. I. therefore wrote to find out what was the experience there as to phthisis cases on these two so different aspects. Dr. Grace of Hilo very kindly replied, telling me that it was universally recognized, though the explanation was unknown, that "the windward is the bad side of the islands."

Thus this lime of inquiry seems to point in the same direction as the last.

\section{Comparison of the Results of Differently Located Sanatoriums.}

Here one enters on especially difficult and delicate ground. Moreover, I imagine the time is scarcely ripe for drawing conclusions of value. "Yet some hints may be gained by considering in what sort of situations the most historically celebrated phthisis health resorts have been established. Dr. E. Campodonico of Lima has recently been so good as to send me particulars of the celebrated resorts in the Peruvian Andes. He writes:

The most famous health resort for phthisical patients in Peru is the territory of Junin, where the towns Tarma, Jauja, Huancayo are located. This region, watered by the river Huancayo are located. This region, watered by the river the eastern side of the Andes. . . . These towns are protected 
by the lofty range of the Andes, which deflects the course of the trade winds, so that any regular wind blowing there can hardly be spoken of. The climate is very dry, and although the rainfall reaches a high point in the months of December, January, and February, when sudden and frequent showers ocur, water dries a way rapidly. oxidized.

Here, therefore, there is an absence of the winds we are discussing.

Again, stillness of atmosphere is a feature on which almost all authorities lay stress in their description of the most successful Alpine resorts. Davos is remarkable in this respect. Writers, too, in no way committed to agreement with my views, have commented on the less satisfactory results obtained at equal Alpine heights, where "wind movement" is greater. Görbersdorf in Silesia, where Brehmer conducted his historical experiment of "open-air" treatment, lies in a very sheltered valley on the north-eastern side of the Carpathians. Nordrach in the Black Forest, where Walther made Brehmer's methods familiar to English medical men, also lies in a very windsheltered valley. Finally, the Darling Downs of Queens land and the Rocky Mountains resorts of Colorado are alike rarely visited by rain-bearing wind.

Thus, a common characteristic of all these successful climates, otherwise so strikingly dissimilar, is their freedom from strong, prevalent, rain-bearing wind.

4. Comparison of the Duration of Fatal Cases Running their Course in Exposed and Sheltered Localities.

Ten years ago a friend who practises on both sides of a high ridge, running nearly due north and south, told me that he had found that his phthisis patients died in a shorter time on its western slope than on its eastern. But it is only lately that the idea has occurred to me of using, as $I$ do here, the recorded durations of the fatal cases.

The information which Dr. J. R. Harper, of Barnstaple, so carefully procured for our joint paper on the influence of strong. prevalent, rain-bearing winds on phthisis prevalence

TABLE I.-Showing the Distribution of 153 Cases of Phthisis in Three Groups of Parishes arranged as in the Former Papcr.

I. Parishes sheltered from S.W., W., and N.W. winds. II. Parishes exposed to N.W. but sheltered from S.W. and W. winds. III. Parishes exposed to S.W., W., and some also to N.W. winds. Deaths at 50 and over are put in parentheses.

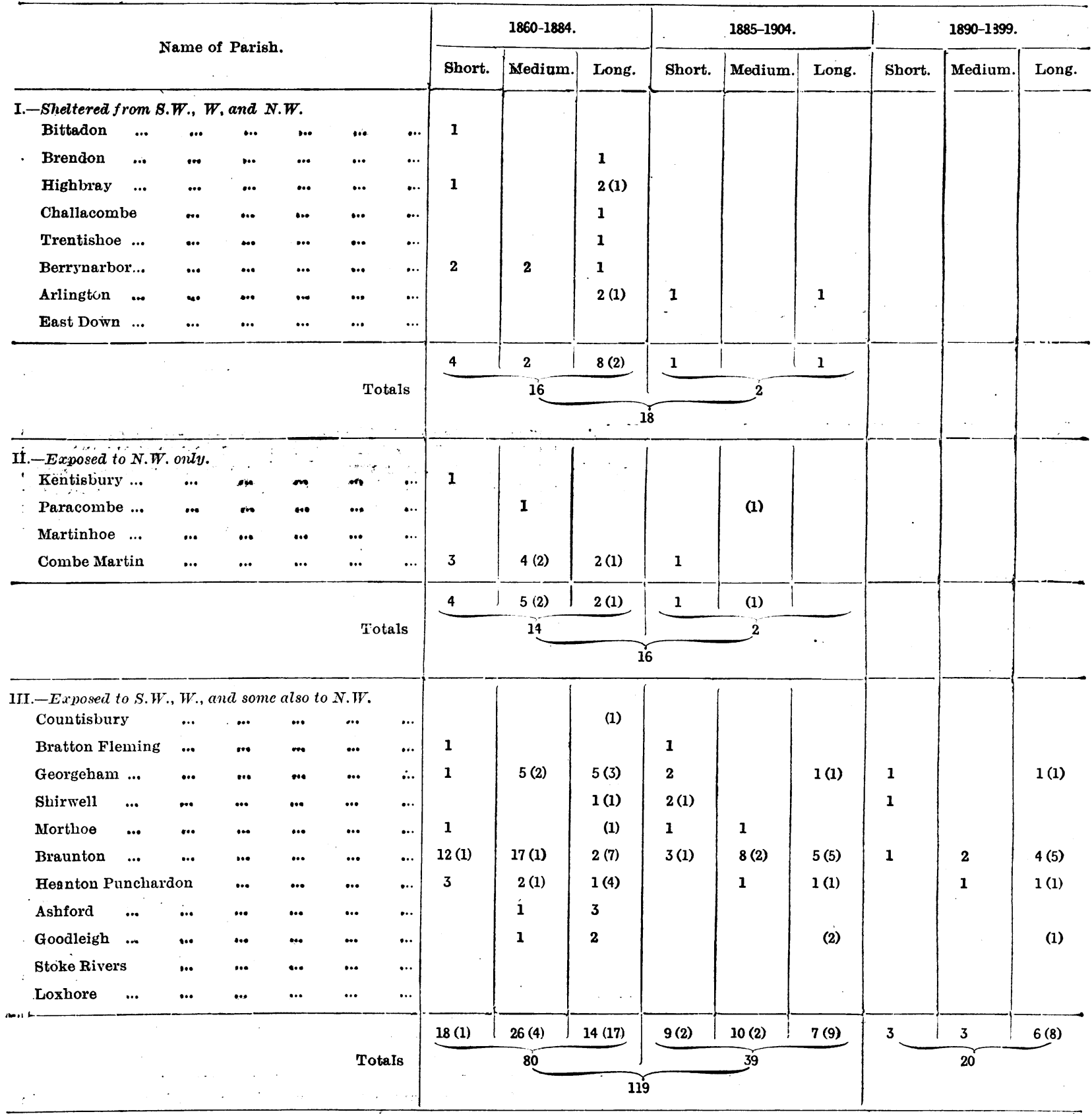


in twenty-three parishes of the Exmoor portion of Barn. staple Rural District during the forty-five years 1860 to 1904, seems to me to furnish just the sort of material requisite. The records used embraced 334 female phthisis deaths over 5 years of age. For 153 of these the duration of the illness was stated, and the tables which follow are based on these 153 cases. The district was one peculiarly fitted for the inquiry, since I was personally fairly well acquainted with it, and it was intimately known to $\mathrm{Dr}$. Harper, so that it was possible to very carefully assess its relative shelters and exposures; its weather had been carefully recorded, and the characters of its soil were well known. For the particulars of each parish and of the district generally I must refer my readers to our original paper or to my recently published book. ${ }^{4}$

I have kept to the divisions of the period used in our inquiry into phthisis prevalence. The twenty years 1885 to 1904 were separately considered, because during them (Koch's discovery having become, presumably, a matter of general knowledge by 1884) diagnosis might be supposed to have become more precise; and an additional reason for now considering the provious twenty-five years, 1860 to 1884 , separately is that after 1884 scarcely any cases with recorded durations occurred in sheltered parishes. Also the decade 1890-99, with remarkably lessened incidence of westerly winds and coincidently low rainfall, obviously should be considered separately from the rest of the period.

In order to compare the durations of the cases I have divided them into three classes-namely, (A) "short" cases, lasting nine months or less; (B) "medium" cases, lasting between ten and fourteen months; and (C) "long" cases, lasting fifteen months or more (Table I).

When we take each of these Groups $I$, II, and III, for the whole forty-five years, and determine the percentages of the total cases formed by the Classes $A, B$, and $C$, respectively, we obtain Table II, which shows that the percentage of "long" cases is much larger in the sheltered parishes than in the exposed, whilst the percentage of "short" cases is practically the same-a very little less in the sheltered parishes. In other words, Table II goes to show that exposure to the wind and rain tends to hasten the course of the disease.

Group II, however, comes out the Rainfal

\begin{tabular}{|c|c|c|c|c|c|}
\hline \multicolumn{6}{|c|}{ TABLE III. -1860 to 1884 . } \\
\hline & & & $\begin{array}{l}\text { III. } \\
\text { (80 Cases.) }\end{array}$ & $\begin{array}{l}\text { II. } \\
\text { (14 Cases.) }\end{array}$ & $\stackrel{\text { I. }}{\text { (16 Cases.) }}$ \\
\hline Long... & $\cdots$ & $\cdots$ & $\begin{array}{c}\text { Per cent. } \\
36\end{array}$ & $\begin{array}{c}\text { Per cent. } \\
21\end{array}$ & $\begin{array}{c}\text { Per cent. } \\
62\end{array}$ \\
\hline Medium & $\cdots$ & $\cdots$ & 38 & 51 & 13 \\
\hline Short & $\ldots$ & $\ldots$ & 26 & 28 & 25 \\
\hline
\end{tabular}

After 1884 we may compare the durations of cases in Group III alone under the varying conditions of wind and

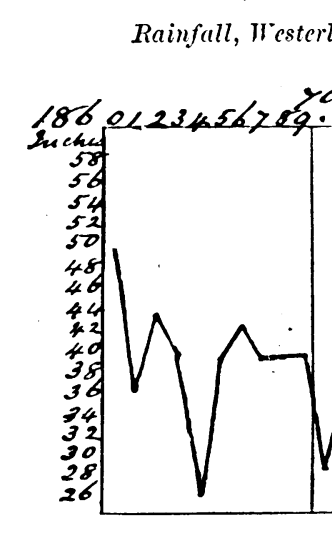
IIind Frequency and Duration
Barnstaple District, 1860-1904.

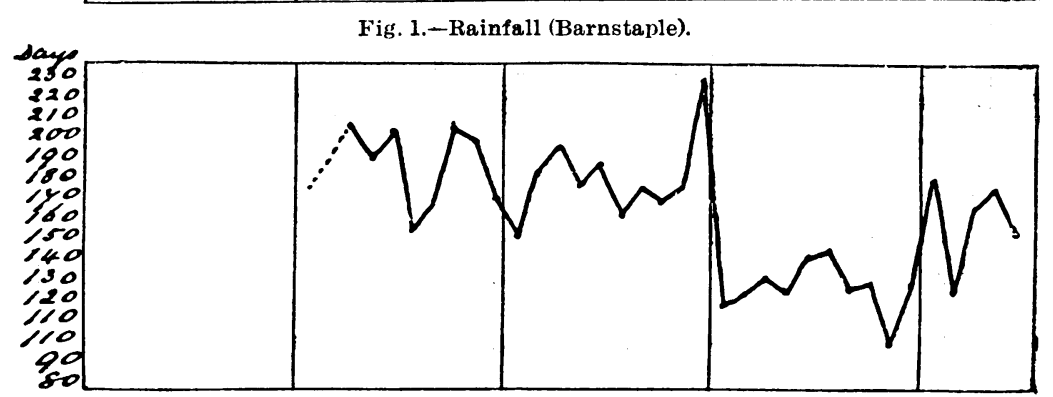
Fig. 2.-Frequency of S.W., W., and N.W, winds (Barnstaple), showing the number of
days on which they blew at 9 a.m.

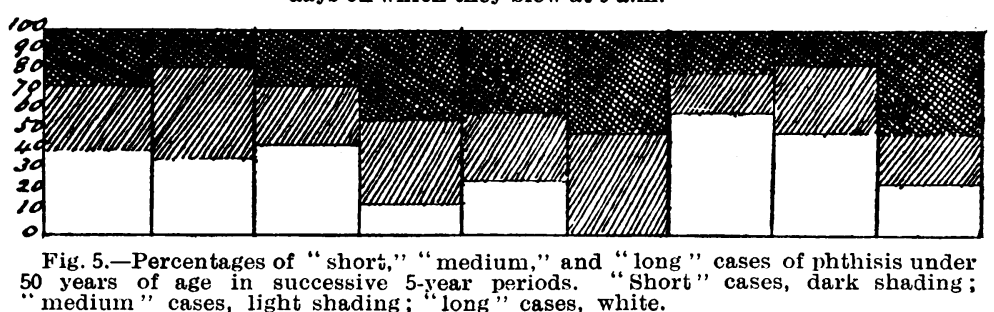

worst of the three; but here another influence has to be taken into account; the parishes of Group II are on the most generally impervious soil, and under a heavy rain. fall-less heavy, indeed, than falls on Group I, but heavier than that on Group III. It is, therefore, a question how much of the shortened durations in this group may be ascribed to the effect of relative dampness of soil.

In the case of the comparison between Groups I and III, however, soil cannot have any share in creating the contrast, since any effect it migbt produce could only be in the direction of diminishing it, since Group III (exposed) has a lower average rainfall and more generally pervious soil than Group I (sheltered).

Taking next the comparison of the three groups during the years 1860 to 1884, Table III is obtained, which is very little different from Table II.

\begin{tabular}{|c|c|c|c|c|c|}
\hline & & & $\begin{array}{l}\text { III. Exposed to } \\
\text { S.W., W., and } \\
\text { some also to } \\
\text { N.W. } \\
\text { (119 Cases.) }\end{array}$ & $\begin{array}{l}\text { II. Exposed to } \\
\text { N.W. only. } \\
\text { (16 Cases.) }\end{array}$ & $\begin{array}{c}\text { I. Sheltered } \\
\text { from S.W., } \\
\text { W.. and } \\
\text { N.W. } \\
\text { (18 Cases.) }\end{array}$ \\
\hline Long... & $\cdots$ & $\ldots$ & ${ }_{36}^{\text {Per cent. }}$ & $\begin{array}{c}\text { Per cent, } \\
18\end{array}$ & $\begin{array}{c}\text { Per cent. } \\
61\end{array}$ \\
\hline Medium & $\ldots$ & $\ldots$ & 36 & 51 & 12 \\
\hline Short & $\ldots$ & $\ldots$ & 28 & 31 & 27 \\
\hline
\end{tabular}

rain, which are shown in the Chart, Figs. 1 and 2. These are shown in Table IV.

TABLE IV.-Group III.

\begin{tabular}{lll|c|c|c}
\hline & & $\begin{array}{c}1860 \text { to } 1884 \\
\text { (80 Cases.) }\end{array}$ & $\begin{array}{c}1885 \text { to } 1904 \\
\text { (39 Cases.) }\end{array}$ & $\begin{array}{c}1890 \text { to } 1899 \\
\text { (20 Cases) }\end{array}$ \\
\hline Long... & $\ldots$ & $\ldots$ & $\begin{array}{c}\text { Per cent, } \\
36\end{array}$ & $\begin{array}{c}\text { Per cent. } \\
42\end{array}$ & $\begin{array}{c}\text { Per cent. } \\
70\end{array}$ \\
Medium & $\ldots$ & $\ldots$ & 38 & 31 & 15 \\
Short & $\ldots$ & $\ldots$ & 26 & 27 & 15 \\
\hline
\end{tabular}

We see that the percentage of "long" cases became much greater and that of the "short" cases became much less during 1890 to 1899 , when the rain and wind were remarkably reduced, than they had been in the wetter and windier period-in other words, Table IV, like Table I, goes to indicate that exposure to wind and rain tends to hasten the course of the complaint.

Elimination of the Influence of Social Advances.

But it might be objected that this lengthening in the duration of the disease in a later period might have been only a concomitant of that steady lessening of phthisis prevalence which has been going on in this country for fifty years or more, owing doubtless to improving social conditions of various sorts. Possibly this is partly true. 
Fig. 3, however, showing the phthisis curve (of deaths occurring in each year) from 1860 to 1904, whilst it illustrates indeed the lessening prevalence, equally indicates the influence of wind and rain; and Fig. 4, showing the annual number of fatal cases originating in each year (obtained approximately from the stated durations), makes this influence of rain and wind even more obvious. In order to discover whether a curve in any way comparable to these curves can be obtained from the durations of phthisis cases, Fig. 5 was constructed ( $o_{-}^{\mathrm{c}}$ the cases dying

Phthisis-Female Deaths in 2.3 Parishes of Burnstaple Rural District.

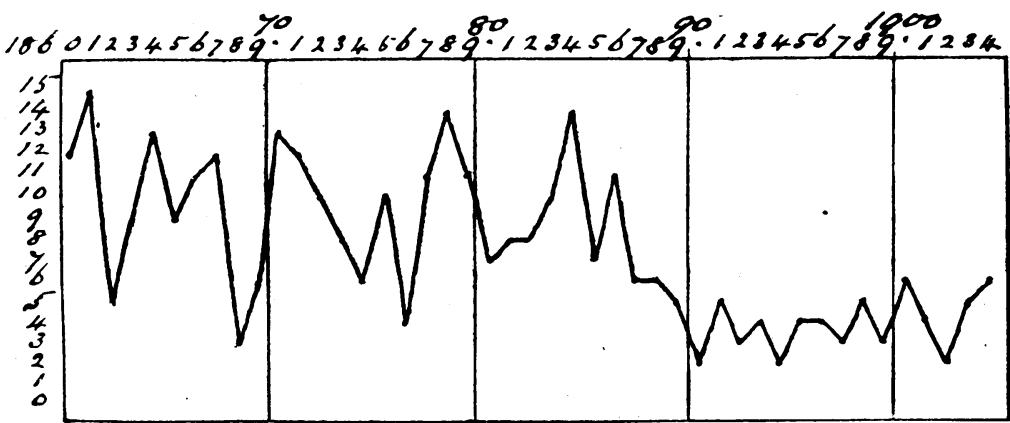

Fig. 3.-All deaths, whether duration is stated or not, referred to the years of their

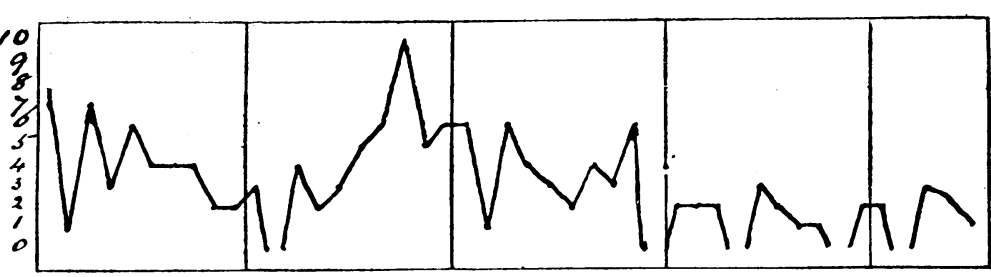

Fis. 4.-All the fatal cases of phthisis whose duration is given referred approximately to their years of origin.

under 50), showing the relative percentage of "short," "medium," and "long" cases in each successive five years between 1860 and 1904. The curve so obtained is, I think, remarkable, indicating most suggestively a relation between (a) rain and wind incidences, (b) phthisis prevalence, and (c) phthisis duration.

Elimination of Error Possibly Caused by Age.

In going through the cases, however, it was impossible to avoid observing how often a "long" duration was associated with an advanced age. Table $\mathrm{V}$ was therefore TABLE V.-Whole 45 Years.

\begin{tabular}{|c|c|c|c|c|}
\hline Ages. & & Short. & Medium. & Long \\
\hline $\begin{array}{lll}-9 & \ldots & \ldots\end{array}$ & $\ldots$ & 1 & 1 & 1 \\
\hline $10-19 \ldots \ldots$ & $\ldots$ & 8 & 8 & 6 \\
\hline $20-29 \ldots \quad \ldots$ & $\ldots$ & 17 & 18 & 14 \\
\hline $30-39 \ldots \quad \ldots$ & $\ldots$ & 9 & 8 & 8 \\
\hline $40-49 \ldots . \quad \ldots$ & $\ldots$ & 3 & 6 & 5 \\
\hline $50-59 \ldots \quad \ldots$ & $\ldots$ & 4 & 4 & 16 \\
\hline $60-69 \ldots . \quad \ldots$ & ... & - & 4 & 9 \\
\hline 70 and over & ... & - & 2 & 3 \\
\hline
\end{tabular}

constructed, to ascertain how far age exercises a disturbing influence.

From this it is obvious that, over 50 years old, age does seem to considerably affect the case-durations. Accord-

TABLE VI.-1860 to 1884, Cascs under 50 .

\begin{tabular}{lll|c|c|c}
\hline & & $\begin{array}{c}\text { III } \\
\text { (50 Cases). }\end{array}$ & $\begin{array}{c}\text { II } \\
\text { (11 Cases). }\end{array}$ & $\begin{array}{c}\text { I } \\
\text { (14 Cases). }\end{array}$ \\
\hline Long... & $\ldots$ & $\ldots$ & Per cent. & Per cent. & Per cent. \\
Medium & $\ldots$ & $\ldots$ & 46 & 46 & 56 \\
Short & $\ldots$ & $\ldots$ & 34 & 36 & 16 \\
\hline
\end{tabular}

TABLE VII.-Group 1II, Cases under 50:

\begin{tabular}{|c|c|c|}
\hline $\begin{array}{c}1860 \text { to } 1884 \\
\text { (50 Cases) }\end{array}$ & $\begin{array}{c}1885 \text { to } 1904 \\
\text { (26 Cases). }\end{array}$ & $\begin{array}{c}1890 \text { to } 1899 \\
\text { (12 Cases) }\end{array}$ \\
\hline $\begin{array}{c}\text { Per cent. } \\
20\end{array}$ & $\begin{array}{c}\text { Per cent. } \\
29\end{array}$ & $\begin{array}{c}\text { Per cent. } \\
50\end{array}$ \\
46 & 38 & 25 \\
34 & 33 & 25
\end{tabular}

ingly, it appeared desirable to recal. culate Tables III and IV with the exclusion of all cases dying at 50 and over. Tables VI and VII were thus obtained. They tend to show even more strikingly than Tables III and IV the unfavourable influence apparently exerted by exposure to the strong, prevalent, rain-bearing winds. Long cases are much commoner and short cases much fewer under the less exposure to rain and wind.

To conclude, it seems to me that these tables and curves, taken in conjunction with the other evidence to which I have-alluded, constitute a considerable prima facie case for the contention that exposure to strong, prevalent, rainbearing winds tends to exercise an unfavourable influence on the course of phthisis. How far treatment may prove equal to neutralizing this unfavourable effect of these rainy winds remains to be seen. The cases here dealt with were mostly treated before the days of modern sanatorium methods.

I take this opportunity of expressing once more my great indebtedness to my friend, Dr. Harper, for the invaluable help his careful information has afforded me.

REFERENCES.

${ }^{1}$ British Journal of Tuberculosis, July, 1910, p. 198. 2 The Treatment of Phthisis, London, 1896, D. 133. 3 Hann's Handbuch dev Klimatologie, vol. i, p. 292. The Infuence of Strong. Prevalent, Rainbearing Winds on the Prevalence of Phthisis, Lewis, London, 1910, 11. 61-78.

\section{Ant Addresz}

ON THE

\section{PREVENTION AND TREATMENT OF PULMONARY TUBERCULOSIS.}

Delivered before the Medical and Scientific Society, University College, Dublin.

By W. M. CROFTON, M.D.,

lecterer in special pathology; Pathologist to Dr. steetexs's HOSPITAL.

Mr. President, Ladies, and Gentlemen,-It is my fir'st duty and pleasure to thank you for the honour you have done me in asking me to deliver the address inaugurating the present session of our society. The subject I have chosen is the prevention and treatment of pulmonary tuberculosis-a subject in which $I$ am myself particularly interested, and one in which every medical practitioner in these countries must take the greatest personal interest, since tuberculosis is the captain of the men of death in these lands, and therefore it must form a large proportion of the cases with which the physician has to deal. Moveover, it is a disease which taxes all one's resources and skill to deal with effectually.

I do not, of course, propose to deal exhaustively with the subject in this short paper, but shall only attempt to emphasize certain measures of prevention and treatment which I think will strengthen our hands in dealing with the disease.

It will be well first to know the mortality and incidence of the disease at the present day. In Ireland last year over 10,000 individuals died of tuberculosis, of which 7,527 